Proceedings

\title{
Spread of Antibiotic Resistance in Aquatic Environments: $E$. coli as a Case Study ${ }^{\dagger}$
}

\author{
Maria Adamantia Efstratiou ${ }^{1, *}$, Marina Bountouni ${ }^{1}$ and Efthimios Kefalas ${ }^{2}$ \\ 1 Department of Marine Sciences, University of the Aegean, 81100 Mytilene, Greece; marbou94@yahoo.gr \\ 2 Laboratory of Water Quality, Regional Authority of North Aegean, 81100 Mytilene, Greece; \\ kefthimios@gmail.com \\ * Correspondence: efstratiou@aegean.gr; Tel.: +30-22510-36815 \\ + Presented at the 3rd EWaS International Conference on "Insights on the Water-Energy-Food Nexus", \\ Lefkada Island, Greece, 27-30 June 2018.
}

Published: 6 August 2018

\begin{abstract}
The aim of this study was to gather information on the spread of antibiotic resistance in Escherichia coli isolates from wells, boreholes and untreated drinking water in islands of Greece. We analyzed for antibiotic resistance 235 E. coli strains isolated from untreated drinking water of small rural communities, and ground water from 4 islands. Resistance was tested against Norfloxacin, Ciprofloxacin, Levofloxacin, Amoxicillin and Cefaclor. More than half (54.9\%) were resistant to at least one of the antibiotics tested. Of these $26.3 \%$ showed multiple resistance (to two or more antibiotics). Strains from drinking water sources were overall more sensitive. Frequent resistance was observed for Amoxicillin (38.3\%) and Levofloxacin (28.5\%), low for Norfloxacin (5.5\%).
\end{abstract}

Keywords: quinolones; cephalosporins; drinking water; ground water; intermediate resistance

\section{Introduction}

Antibiotic resistant microorganisms have become, the last few decades, a challenge to infection control. Antibiotics appear with increased frequency to be less effective against microorganisms and, depending on the pathogen, the incurable infections are threatening to become an everyday phenomenon resulting in increased fatality. The current resistance to antimicrobial drugs has been estimated to account for 700,000 deaths a year. If the antimicrobial resistance increases it is predicted to account for 10,000,000 deaths/year by 2050 [1].

In the environment antibiotic resistant bacteria accumulate, arising either by accidental mutation, by mutation in humans or animals under antibiotic treatment selection or are naturally occurring environmental bacteria who, under selective pressures (an evolutionary response resulting from natural selection) have developed resistance for their own protection against competitors [2]. Resistance genes from environmental bacteria can be transferred to clinically important pathogens via horizontal gene transfer, pointing to the fact that environment is an important component of spread of antibiotic resistance to humans.

The amount of antibiotics consumed by humans is phenomenal. In livestock, too, excessive amounts are used for growth promotion and as feed additives, as well as in veterinary medicine. Antibiotic resistant bacteria from both sources are excreted through waste and are dispersed into aquatic environments either directly or by effluents of Waste Water Treatment Plants discharged in surface waters. In many countries deposition of manure or sludge on land as a fertilizer is a widespread practice. So is the use of WWTP effluents for irrigation and urban applications. Underground aquifers can be affected indirectly. The demand for water has led to use of WWTP effluent for replenishing aquifers, so antibiotic resistant bacteria, which have survived treatment processes, can be injected in aquifers directly. Aquaculture practices, the administration of antibiotics 
to fish for disease prevention or therapeutically, charges the aquatic environment with excess antibiotics leading to possibility of antibiotic resistant bacteria in aquaculture products.

Drinking water is a particularly important milieu for dissemination of such bacteria, which could infect the general population producing serious Pubic Health consequences. Several investigations have been conducted on the occurrence of antibiotic resistance and multiresistance in drinking water. As early as 1981 in an extensive investigation of drinking water in the USA, $33.9 \%$ of the 2653 heteroptophic gram positive and gram negative bacteria isolated were found multiresistant, and of these $2.9 \%$ were resistant to all 5 antibiotics tested [3]. Massa et al. [4] isolated heterotrophic resistant bacteria from bottled mineral water in Italy, of which $51 \%$ were multiresistant. More recently heterotrophic bacteria from drinking water in the USA, before and after treatment, were found resistant to amoxicillin (3.0-39.6\%), to ciprofloxacin (0.2-13.4\%), to rifampicin (10.8-82.1\%) and to lesser extend to other antibiotics [5]. In a U.K. investigation 77.7\% of heterotrophic bacteria from tap water were resistant to at least one antibiotic, $40.6 \%$ had multiple resistance. Amoxicillin resistance was the most prevalent (64.9\%), 8.8\% were detected to resist in ciprofloxacin [6]. In Greece $91.3 \%$ of antibiotic resistant gram negative bacteria isolated from drinking water (mainly enterobacteriaceae, vibrionaceae and Pseudomonas sp.) were multiresistant. The highest resistance was to cephalotin, ampicillin and carbenicillin. No resistance was detected for quinolones, aminoglycosides, imipenem, aztreonam, ceftazidime or cefoperazon [7]. All 32 injured coliforms recovered from drinking water in Argentina, Klebsiella oxytoca, Enterobacter aerogenes and Enterobacter cloacae, were resistant to aminopenicillin-sulbactam and nitrofurantoin while they were sensitive to the quinolones tested (norfloxacin and ofloxacin) [8].

Patterns of antibiotic resistance of E. coli strains isolated from drinking water have been described in very few countries. In India all E. coli strains recovered from chlorinated drinking water of a tropical city were multiresistant to at least 4 antibiotics, $100 \%$ were resistant to nalidixic acid, $95 \%$ to amoxicillin, $25 \%$ to norfloxacin, $10 \%$ were resistant to ciprofloxacin [9]. In a study in China $49.5 \%$ of isolates from drinking water sources before treatment were resistant to at least one antibiotic. $24.0 \%$ exhibited multiple resistance. Amongst the 18 antibiotics tested, the strains showed the highest resistance to amoxicillin, ciprofloxacin and levofloxacin [10]. In Pakistan in a study examining resistance patterns to 2 antibiotics, $29.0 \%$ of $E$. coli from tap water were resistant to kanamycin and ampicillin [11]. In another investigation $63.0 \%$ of $E$. coli isolates from drinking water were multiantibiotic resistant, $92.6 \%$ were resistant to nalidixic acid, $88.9 \%$ to ampicillin, $40.7 \%$ to ceftriaxone, $37.0 \%$ to ciproflaxin [12]. In Canada $10.5 \%$ of the E. coli isolated from private drinking water sources were resistant to minimum one antibiotic, 3.7\% to more than 3 antibiotics [13].

Not many studies are published investigating the problem of antibiotic resistance in bacteria from ground water used for drinking purposes. In 1988 Amundson et al. [14] reported that in well water $45 \%$ of total coliforms and $16 \%$ of fecal coliforms were multiresistant, with resistance most commonly to ampicillin, cephalotin, nitrofurantoin and tetracycline. In a study of rural untreated groundwater supplies, $100 \%$ of the non-coliform bacteria and $87 \%$ of the coliforms isolated were resistant to at least one antibiotic of the 16 antibiotics tested. Novobiocin, cephalotin and ampicillin were the antibiotics toward which the highest resistance was directed. Multiresistant were $60 \%$ of the coliforms-of which $14 \%$ were E. coli. Above $95 \%$ of non-coliforms exhibited multiple resistance patterns [15]. In Egypt, in a study recently published, three E. coli strains were isolated from ground water, all of them multiresistant [16].

Should humans contact-or consume-antibiotic resistant microorganisms and submit to infection, the possibility of successful antibiotic treatment is severely reduced. The widespread enrichment of environmental waters with antibiotic resistant bacteria and genes make it plausible that such bacteria find their way into drinking water sources, survive treatment processes and create public health issues. In Greece the wide consumption of antibiotics and the development of resistant bacterial strains to even the most advanced antibacterial drugs [17] is the cause of grave concern. In this study we used Escherichia coli strains isolated from water sources (groundwater and untreated drinking rural community water) to address the questions: 1 . Which is the sensitivity of these faecal organisms to 5 antibiotics. 2. What is the resistance patterns of simple- versus multi-resistance. 


\section{Materials and Methods}

\subsection{Site Description}

Fresh water samples were collected from four Greek islands (Figure 1). The drinking water was untreated and came from small rural communities; the ground water was collected from boreholes and wells from the same islands. It is used mostly for irrigation.
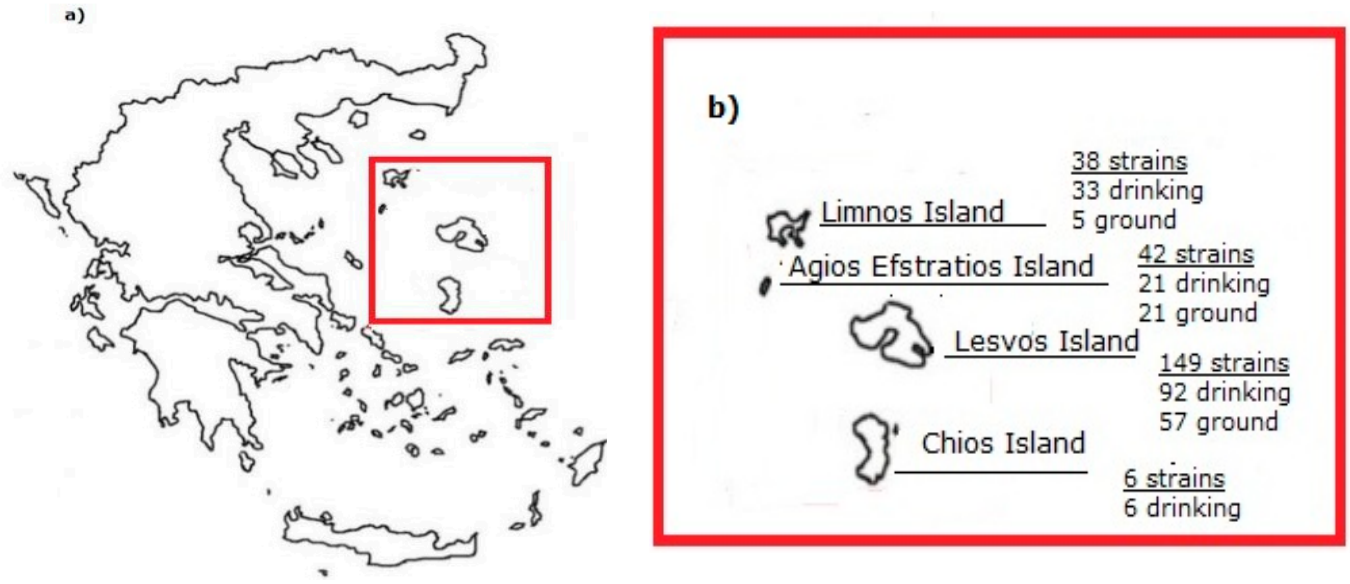

Figure 1. Sampling areas: (a) map of Greece; (b) the four Greek islands and number of isolated E. coli strains from each.

\subsection{Sample Collection}

Sampling was conducted according to ISO 19458:2006throughout 2017. The samples were collected in $500 \mathrm{~mL}$ dark glass sterile bottles and carried to the Laboratory on ice. Upon arrival their temperature was recorded, and was between $2.0-8.0^{\circ} \mathrm{C}$. They were processed within a maximum of $24 \mathrm{~h}$ from collection.

\subsection{Escherichia coli Isolation}

235 strains of E. coli were isolated by membrane filtration (ISO 9308-1:2014). 158 strains came from the drinking, untreated water, 77 strains were from ground water sources. Membranes were placed on Chromocult Coliform Agar (Merck cat.no. 1.10426.0500). $\beta$-D-galactosidase positive colonies (dark-blue to violet color) were transferred and incubated on Tryptic Soy Agar (Merck cat.no. 1.05458.0500). Oxidase negative colonies were transferred in Tryptone Water (Merck cat.no.VM 610494.346) to perform Indole test (ISO 8199:2005). Colonies positive for indole and for $\beta$ D-galactosidase tests were considered as Escherichia coli.

\subsection{Antibiotic Resistance}

The resistance of the $235 \mathrm{E}$. coli strains was tested against five antibiotics widely used in medicinal and veterinary practice: three quinolones (Norfloxacin-NXN, Ciprofloxacin-CIP, Levofloxacin-LVX) one cephalosporin (Cefaclor-CEC) and one penicillin (Amoxicillin-AMX) Becton Dickinson. Amoxicillin is a relatively 'old' antibiotic, came into use in 1972, and belongs to the penicillin group. Quinolones are amongst the more recent additions to the antibiotic family, and are considered very effective. Norfloxacine was introduced in the $80^{\prime} \mathrm{s}$, Ciprofloxacine in the $90^{\prime} \mathrm{s}$, Levofloxacine around 2000. Escherichia coli strain CRM09001L was used for quality control of the screening protocol. The bacteria were tested by the Kirby-Bauer disk diffusion susceptibility test [18]. Interpretation of results was conducted based on the EUCAST Testing Guidelines-European Committee on Antimicrobial Susceptibility [19], and strains were classified as 'resistant', 'intermediate' or 'sensitive' (Table 1). Strains exhibiting "intermediate" resistance patterns were classified as "resistant" for the purposes of this study. 
Table 1. Concentration $(\mu \mathrm{g})$ of antibiotics and diameter $(\mathrm{mm})$ of inhibition zones.

\begin{tabular}{ccccc}
\hline & & \multicolumn{3}{c}{ Inhibition Zone mm } \\
\hline Antibiotic & Concentration & Resistant & Intermediate & Sensitive \\
\hline Amoxicillin AMX & $25 \mu \mathrm{g}$ & $\leq 1.3$ & $1.4-1.6$ & $\geq 1.7$ \\
Cefaclor CEC & $30 \mu \mathrm{g}$ & $\leq 1.4$ & $1.5-1.7$ & $\geq 1.8$ \\
Norfloxacin NXN & $10 \mu \mathrm{g}$ & $\leq 2.0$ & $2.1-2.4$ & $2.5-3.1$ \\
Ciprofloxacin CIP & $5 \mu \mathrm{g}$ & $\leq 2.4$ & $2.5-2.7$ & $2.8-3.5$ \\
Levofloxacin LVX & $5 \mu \mathrm{g}$ & $\leq .5$ & $2.6-2.8$ & $2.9-3.6$ \\
\hline
\end{tabular}

\section{Results}

Of the 235 E. coli strains we examined more than half (54.9\%) were resistant to at least one of the antibiotics tested. Of these $26.3 \%$ showed multiple resistance (to two or more antibiotics). $13.6 \%$ were resistant to two antibiotics, $9.8 \%$ were triply resistant, $0.8 \%$ were quardriply resistant and $2.1 \%$ were resistant to the five antibiotics tested (Table 2).

Table 2. Escherichia coli strains resistant to one or more antibiotics.

\begin{tabular}{|c|c|c|c|}
\hline Resistance to: & Drinking Water & Ground Water & Total \\
\hline & Strains (\%) ${ }^{1}$ & Strains (\%) 1 & Strains (\%) ${ }^{1}$ \\
\hline 1 antibiotic & $41(25.9)$ & $26(33.8)$ & $67(28.5)$ \\
\hline 2 antibiotics & $23(14.6)$ & $9(11.7)$ & $32(13.6)$ \\
\hline 3 antibiotics & $11(7.0)$ & $12(15.6)$ & $23(9.8)$ \\
\hline 4 antibiotics & - & $2(2.6)$ & $2(0.8)$ \\
\hline 5 antibiotics & $5(3.1)$ & - & $5(2.1)$ \\
\hline Total strains & $80(50.6)$ & $49(63.7)$ & $129(54.9)$ \\
\hline
\end{tabular}

${ }^{1}$ Percentage of the total (235) number of strains examined.

Strains from drinking water sources were overall more sensitive, although by little, exhibiting lower multiple resistance patterns $(24.7 \%$ as opposed to $29.9 \%$ of the ground water strains). More specifically, 80 of the 158 E. coli strains from drinking untreated water (50.6\%) were resistant to at least 1 antibiotic. Half of these (41-25.9\%) were resistant to only one antibiotic, five (3.1\%) were resistant to all 5 antibiotics tested. Ground water E. coli had higher percentages of resistance: of the 77 strains examined $49(63.7 \%)$ showed resistance to one or more antibiotics. Although the percentage of resistant strains was higher, more than half of them (26-33.8\%) were resistant to only one antibiotic, only two (2.6\%) were resistant to 4 antibiotics, none resisted all 5 tested (Figure 2).

Amoxicillin was the antibiotic with the highest resistance response $(38.3 \%)$ followed by Levofloxacin (28.5\%), Cefalosporin, (18.3\%), Ciprofloxacin (8.5\%) and Norfloxacin (5.5\%). In drinking and in ground water the patterns of resistance were the same: in Amoxicillin the highest resistance, in Norfloxacin the lowest. There was no antibiotic, of those tested, to which $100 \%$ of the isolates were susceptible (Table 3). 

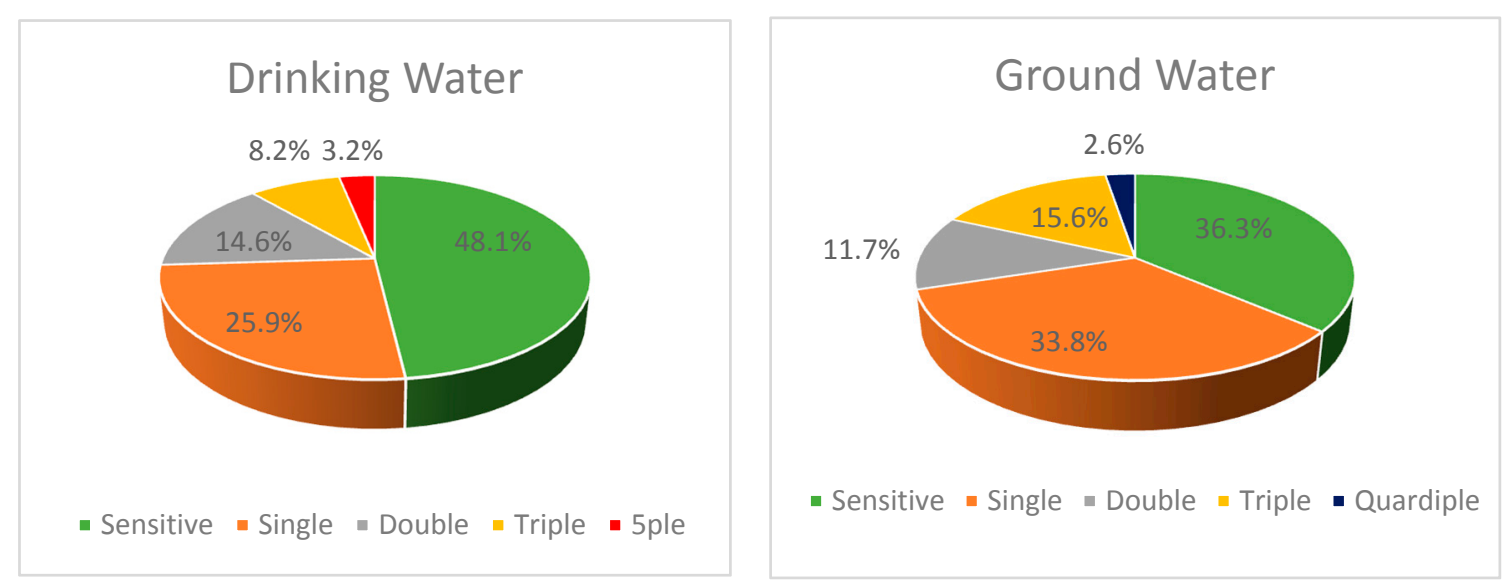

Figure 2. Frequency of resistance of E. coli strains isolated from drinking and ground water to 5 antibiotics.

Table 3. Resistance of E. coli strains to 5 antibiotics.

\begin{tabular}{cccccc}
\hline & $\begin{array}{c}\text { AMX } \\
\text { Number }^{1}-\%\end{array}$ & $\begin{array}{c}\text { CEC } \\
\text { Number }^{\mathbf{1}}-\%\end{array}$ & $\begin{array}{c}\text { NXN } \\
\text { Number }^{1}-\%\end{array}$ & $\begin{array}{c}\text { CIP } \\
\text { Number }^{\mathbf{1}} \mathbf{- \%}\end{array}$ & $\begin{array}{c}\text { LVX } \\
\text { Number }^{\mathbf{1}}-\%\end{array}$ \\
\hline Drinking & $54-34.2 \%$ & $29-18.4 \%$ & $9-5.7 \%$ & $11-7.0 \%$ & $42-26.6 \%$ \\
Ground & $36-46.8 \%$ & $14-18.2 \%$ & $4-5.2 \%$ & $9-11.7 \%$ & $25-32.5 \%$ \\
Total & $90-38.3 \%$ & $43-18.3 \%$ & $13-5.5 \%$ & $20-8.5 \%$ & $67-28.5 \%$ \\
\hline
\end{tabular}

1 Number of resistant strains; AMX-amoxicillin; CEC-cefaclor; NXN-norfloxacin; CIPciprofloxacin; LVX-levofloxacin.

\section{Discussion}

The results of our investigation showed that resistance to antibiotics is widespread amongst $E$. coli that proliferate untreated water used for drinking purposes in small rural communities in four Greek islands. According to several authors [9-14] the situation is not overall different in other countries. In every research project looking for E. coli or faecal coliforms in drinking water there were strains exhibiting resistance to antibiotics. The differences were in the percentages which ranged from $100 \%$ resistant strains in India [9], to $10.5 \%$ in Canada [13]. In our research we found $50.6 \%$ to be resistant to at least one antibiotic. Our observations in multiresistance patterns are not similar with these of other research teams. We had multiresistance in $24.7 \%$ of our strains from drinking water sources. The findings of other authors ranged from 100\% in India [9] to 3.7\% in Canada [13]. The higher percentages in resistant strains were reported from countries where the use of antibiotics in humans and animals is less strictly controlled.

In ground water $63.6 \%$ of our strains showed resistance to one or more antibiotics. Of these $29.9 \%$ were multiresistant. This is not different from results elsewhere. In an early study in the US [14] it was reported that $16 \%$ of faecal coliforms isolated from well water was multiresistant. In a study published 26 years later [15] 87\% of coliform bacteria isolated from ground water in the US were multiresistant. Of these 14\% were E. coli. In Egypt [16] 100\% of E. coli isolated from groundwater exhibited multiple resistance. All investigators report single resistance to be more often met than multiple resistance. It is worth noting that the more antibiotics the strains are tested against, the more multiresistant findings.

Because of the very small number of relevant studies internationally, and to the fact that in each study a different set of antibiotics is examined, it is not possible to perform a comparison as to resistance patterns of waterborne E. coli strains. Amoxicillin is an antibiotic against which most bacteria from our study had resistance genes (34.2\%), 95.0\% resistance was documented in India [9]. Ciprofloxacin and Levofloxacin, second and third generation quinolones, are antibiotics heavily 
prescribed, and this reflects in the fact that we observed high resistant $E$. coli strains (11.7\% and 32.5\%) to these two antibiotics in ground water.

The existence of $E$. coli in drinking water is in itself disturbing. In countries with high standards of living it is attributed mostly to the fact that there exist many families who live in farms and remote locations, where there is no mains connection and water used for drinking comes from private, untreated sources. The existence of so many antibiotic resistant strains of this bacterium is alarming, given the fact that not only E. coli itself could under certain circumstances, cause illness, but even more because of the ability of the resistance genes to transfer amongst microorganisms, transferring the resistance genes to pathogens. Our work demonstrates that untreated drinking and ground water can contribute to the spreading of antibiotic resistance to the general population, posing a serious challenge to infection control.

Author Contributions: M.A.E. conceived and designed the experiments; M.B. performed the experiments under the su-pervision of E.K.; M.A.E. and M.B. analyzed the data; all three authors contributed in the writing of the paper, read and approved the manuscript.

Conflicts of Interest: The authors declare no conflict of interest.

\section{References}

1. O'Neill, J. Tackling Drug-Resistant Infections Globally: Final Report and Recommendations the Review on Antimicrobial Resistance; Welcome Trust: London, UK, 2016. Available online: https://amrreview.org/sites/default/files/160518_F inal\%20paper_with\%20cover.pdf (accessed on 19 January 2018).

2. Seiler, C.; Berendonk, T.U. Heavy metal driven co-selection of antibiotic resistance in soil and water bodies impacted by agriculture and aquaculture. Front. Microbiol. 2012, 3, 399. doi:10.3389/fmicb.2012.00399.

3. Armstrong, J.L.; Calomiris, J.J.; Seidler, R.J. Selection of antibiotic-resistant standard plate count bacteria during water treatment. Appl. Environ. Microbiol. 1981, 44, 308-316. Available online: https://www.ncbi.nlm.nih.gov/pmc/articles/PMC242011/ (accessed on 12 January 2018).

4. Massa, S.; Petruccioli, M.; Fanelli, M.; Gori, L. Drug resistant bacteria in non carbonated mineral waters. Microbiol. Res. 1985, 150, 403-408. Available online: https://www.ncbi.nlm.nih.gov/pubmed/8564367 (accessed on 19 February 2018).

5. Xi, C.; Zhang, Y.; Marrs, C.F.; Ye, W.; Simon, C.; Foxman, B.; Nriagu, J. Prevalence of antibiotic resistance in drinking water treatment and distribution systems. Appl. Environ. Microbiol. 2011, 75, 5714-5718. doi:10.1128/AEM.00382-09.

6. Khan, S.; Knapp, C.W.; Beattie, T.K. Antibiotic resistant bacteria found in municipal drinking water. Environ. Process. 2016, 3, 541-552. doi:10.1007/s40710-016-0149-z.

7. Papandreou, S.; Pagonopoulou, O.; Vantarakis, A.; Papapetropoulou, M. Multiantibiotic resistance of gram-negative bacteria isolated from drinking water samples in southwest Greece. J. Chemother. 2013, 12, 267-273. doi:10.1179/joc.2000.12.4.267.

8. Cordoba, M.A.; Roccia, I.L.; De Luca, M.M.; Pezzani, B.C.; Basualdo, J.A. Resistance to antibiotics in injured coliforms isolated from drinking water. Microbiol. Immunol. 2001, 45, 383-386. doi:10.1111/j.13480421.2001.tb02634.x.

9. Pantak, S.P.; Gopal, K. Prevalence of bacterial contamination with antibiotic resistant and enterotoxigenic fecal coliforms in treated drinking water. J. Toxicol. Environ. Health A 2008, 71, 427-433. doi:10.1080/15287390701838796.

10. Chen, Z.; Yu, D.; He, S.; Ye, H.; Zhang, L.; Wen, Y.; Zhang, W.; Shu, L.; Chen, S. Prevalence of antibioticresistant Escherichia coli in drinking water sources in Hangzhou city. Front. Microbiol. 2017, 8, 1133. doi:10.3389/fmicb.2017.01133.

11. Samra, Z.Q.; Naseem, M.; Khan, S.J; Dar, N.; Athar, M.A. PCR targeting of antibiotic resistant bacteria in public drinking water of Lahore metropolitan, Pakistan. Biomed. Environ. Sci. 2009, 6, 458-463. doi:10.1016/S0895-3988(10)60002-5.

12. Patoli, A.A.; Patoli, B.B.; Mehraj, V. High prevalence of multi-drug resistant Escherichia coli in drinking water samples from Hyderabad. Gjms 2010, 8, 23-26. Available online: http://www.gjms.com.pk/files/ GJMS\%20Vol-8-1(5).pdf (accessed on 8 January 2018). 
13. Coleman, B.L.; Louie, M.; Salvadori, M.I.; McEwen, S.A.; Neumann, N.; Sibley, K.; Irwin, R.J.; Jamieson, F.B.; Daignault, D.; Majury, A.; et al. Contamination of Canadian private drinking water sources with antimicrobial resistant Escherichia coli. Water Res. 2013, 47, 3026-3036. doi:10.1016/j.watres.2013.03.008. Available online: https://www.ncbi.nlm.nih.gov/pubmed/23548566 (accessed on 19 February 2018).

14. Amundson, D.; Lindholm, C.; Goyal, S.M.; Robinson, R.A. Microbial pollution of well water in southeastern Minnesota. J. Environ. Sci. Health A 1988, 23, 453-468. doi:10.1080/10934528809375425.

15. McKeon, D.M.; Calabrese, J.P.; Bissonnette, G.K. Antibiotic resistant gram-negative bacteria in rural groundwater supplies. Water Res. 1995, 29, 1902-1908. doi:10.1016/0043-1354 (95)00013-B.

16. AbdelRahim, K.A.A.; Hassanein, A.M.; AbdelAzeiz, H.A.E.H. Prevalence, plasmids and antibiotic resistance correlation of enteric bacteria in different drinking water resources in Sohag, Egypt. Jundishapur J. Microbiol. 2015, 8, e18648. doi:10.5812/jjm.18648.

17. Wellington, E.M.H.; Boxall, A.B.A; Cross, P.; Feil, E.J.; Gaze, W.H.; Hawkey, P.M.; Johnson-Rollings, A.S.; Jones, D.L.; Lee, N.M.; Otten, W.; et al. The role of the natural environment in the emergence of antibiotic resistance in Gram-negative bacteria. Lancet Infect. Dis. 2013, 13, 155-165. Available online: https://www.ncbi.nlm.nih.gov/pubmed/23347633 (accessed on 19 February 2018).

18. Hudzicui, J. Protocol 3189 Kirby-Bauer disk diffusion susceptibility test. ASM Sci. 2009, 1-23. Available online: http://www.asmscience.org/content/education/protocol/protocol.3189 (accessed on 18 May 2017).

19. Matuschek, E.; Brown, D.F.J.; Kahlmeter, G. Development of the EUCAST disk diffusion antimicrobial susceptibility testing method and its implementation in routine microbiology laboratories. Clin. Microbiol. Infect 2014, 20, O255-O266. doi:10.1111/1469-0691.12373. Available online: https://www.ncbi.nlm.nih.gov/pubmed/24131428 (accessed on 2 December 2017).

(C) 2018 by the authors. Licensee MDPI, Basel, Switzerland. This article is an open access article distributed under the terms and conditions of the Creative Commons Attribution (CC BY) license (http://creativecommons.org/licenses/by/4.0/). 